blished for physiological research, we cannot hope to do much in the way of advancing the scientific basis of medicine. When we consider what is done by Germany, and see her now facile princeps in war, as also in all that relates to the advancement of science, we must bestir ourselves if we are to maintain the position among the nations which we persuade ourselves we hold. A step in the right direction has been taken by the Council of the College of Surgeons. They now require of all those who present themselves for examination satisfactory proof that they have made themselves acquainted with the principles and methods of experimental research.

The next thing that requires to be done is the establishment of laboratories for that purpose. This is now being effected. In this way we hope soon to see a new era inaugurated in the prospects of scientific medicine in this country: for when all our students have it in their power to learn the methods of physiological investigation, and their practical application to therapeutics, we shall be the better able to sift fact from tradition and hypothesis, to clear up what is doubtful, and sweep away the fallacies on which quacks flourish and by which medicine is disgraced.

\section{CASE OF IDIOPATHIC MYELITIS.}

\section{By MARTIN G. B. OX LEY, I.K.Q.C.P.I., Physician to the Liverpool Infirmary for Children.}

Thos. MCDFrMot, aged II, a strong healthy-looking boy, was admitted to the Infirmary on February 24 th, 1870 . He stated that, about one week before almission, pains commenced in the small of his back, and gradually extended round his body on both sides, as high in front as the umbilicus. The pains were very much worse at night, preventing him from sleeping. Micturition was frequent, giving him temporary rclicf. Waiking caused severe pain. He had received no injury, and was in perfect health previously to the attack.

On admission, his condition was as follows. The pulse was 120 ; the tongue coater ; the skin hot. His countenance was expressive of great pain. The body was inclined slightly forward. He was unable to assume the crect posture. He could not walk without causing great increase of pain. The pain over the lower dorsal vertebræ was very severe ; it extended round the abdomen and down the lower extremities, and was greatly increased by pressure over the spinous processes. Micturition was very frequent. The bowels were costive. Sensibility was nowhere impaired. The skin was red over the lower dorsal vertebra.

February 26th. Pulse I 6 ; temperature 103.2. He seemed much worse, and had profuse perspirations. The pain was constant in the legs, and there was slight hyperesthesia. Constant pain, increased by pressure, continued in the back. He jumped up frequently in the night and cried out with pain. Incontinence of urine, constipation, and priapism, now existed.

March $3 \mathrm{rd}$. There was complete paralysis of the lower extremities; anæsthesia extended upwards as far as the seventh intercostal space in front and the fifth dorsa! vertebra behind, above which slight hyperesthesia existed. The freces and urine were passed involuntarily. The priapism continued. He had a burning pain in the back, increased by pressure. The temperature in the groin was I02. I ; in the axilla Ioo.4. Bedsores were forming over the sacrum and the trochanters of the thigh-bones. All the symptoms continued unchanged till April, when the bed-sores were rapidly extending, completely exposing the sacrum posteriorly, and the trochanters and head of the femur on each side. He died on April I 8th.

Post Mortim Examination. - Inflammatory lymph extended over the lower dorsal portion of the spinal cord. The membranes here were very much injected, and partially adherent to bone, particularly posteriorly. On laying oren the membranes, nothing abnormal was observed. A longitudinal incision of the cord showed white softening to the extent of half an inch opposite the fifth dorsal vertebra; and whitish fluid exuded here. The vertebre were perfectly healthy. On removing the calvaria, the dura mater was not so vascular as is usual. There was slight subarachnoid effusion, general over the upper surface. At several points along the longitudinal fissure, clusters of minute white nodules resembling tubercle were situated on the arachnoid. The substance of the brain, on section, seemed very anxmic. At the base, slight adhesions and a few minute white nodules were observed. The bladder was found firmly contracted. In its walls, at the apex, was an abscess of the size of a hazel-nut. The interior of the bladder was ulcerated. The ureters were greatly dilated. The pelvis of the kidney was much enlarged and ulcerated. Points and patches of a brown colour with gritty particles, were scattered ihere and there through the substance of the kidneys. The renal structure was very pale; and numerous abscesses were present on the surface of both kidneys.

\section{ON THE SHOULDER-TIP PAIN, AND OTHER SYMPATHETIC PAINS, IN DISEASES OF THE LIVER.*}

By DENNIS EMBLETON, M.D., Physician to the Infirmary, Newcastle-upon-Tyne.

OF the group of symptoms ordinarily representing a disease of some internal organ, there are usually a few primary, central, and distinctive members, forming, as it were, the nucleus, and which are directly referable to the organ itself; to these are frequently added others more outlying or peripheral and less characteristic, indicating the influence exerted by the diseased organ upon parts, more or less distant it may be, but more or less importantly connected with it. Parts thus secondarily affected have been said to sympathise with the primarily diseased organ.

The study of the sympathies, morbid or healthy, of the different organs or parts of the body, obscure, intricate, and difficult, has from the earliest ages riveted the attention of Physicians, who in their earnest strivings after truth, have been led astray into the wildest conjectures and vainest hypotheses.

Within the past century, however, an increasing light has been dawning upon this part of our science. Thus we can, to a certain extent, account for the pain in the knee in hip-joint disease, through the connection of the knee and hip-joints by means of branches of the anterior crural and obturator nerves, and so on for other examples.

It must, however, be allowed that these explanations, such as they are, are neither full nor satisfactory; they only show that these pains do occur in certain cases, and that the parts concerned have certain more or less direct nervous interconnections, but they fail to inform us of the nature or essence of the sympathy existing, of the mode in which it is evoked, and of the good, if there be any, that comes of it; and the mystery of sympathy remains as great as before. And yet there can be little doubt that all the sympathetic pains we meet with are susceptible of satisfactory explanation, could we only examine them with sufficient care, and by reference to trustworthy anatomy.

The shoulder-tip pain in liver-disease belongs confessedly to the same category of sympathetic affections as that just named, but I have not been able to find any sufficiently satisfactory explanation of it, even to the extent to which explanation has been carried in the other instances.

The object proposed in this paper is to attempt an explanation which shall be plain and satisfactory, and shall dispel the ancient mystery which hangs around and obscures the morbid sympathy of organs.

As a preliminary, however, it may be interesting to glance at what has been written on the subject, for this pain has received a good share of attention from the time of the father of medicine, and probably long before, down to the present day.

For convenience, several quotations have been placed in foot-notes. I. Ancient Authors. - Hippocrates, $\dagger$ Celsus, $\ddagger$ Galen, Aretæus, $\$$ Coelius Aurelianus, \#Paulus AEgineta, $\mathrm{T}$ aly Abbas, and Rhazes, all mention the existence of pain in liver-disease in the shoulder, clavicle, or throat of the right side. Prosper Alpinus** notices it as occurring in the right side of the throat and the right scapula.

* Read in the Medical Section at the Annual Meeting of the British Medical Association in Newcastle-upon-Tyne, August 1870 .

"Pains in the shoulder, which, passing down the arms, occasion torpor and pains, do not usually terminate in deposits, but the patients get better by vomitin black bile. But when the pains remain in the shoulder, or extend to the back, the patients are relieved by vomiting pus or black bile. But if they have more difficulty of breathing, or if there be any unusual colour on the countenance, whether reddish or black, it is to be expected that they will rather spit blood."-(The Genuine Works of Hippocrates, by F. Adams, LL.D., Append. to Prognost., vol. i, p. 268 . Sydenham Society, I848.

‡ In Acute Hepatitis. - "Dextrâ parte sub præcordiis vehemens dolor est ; idemque ad latus dextrum et ad jugulum humerumque partis ejusdem pervenit; nonnunquam manus quoque dextra torquetur."-(A. Corn. Celsi Med, libri octo, by Milligan, lib. iv, viii.

$\$$ "The diaphragm and succingens (pleura) are dragged downwards, for from them the liver is suspended as a weight. For this reason, a strong pain extends to the clavicle of the same side."-(Extant Works of Aretæus the Cappadocian, by F. Adams, LL. D. Acute Diseases, book ii, cap. vii, p. 277. Syd. Soc., r856.) If "The symptoms of scirrhus of the liver are a round circumscribed tumour, felt below the ribs, the cor scirrhus of the liver are a round circumscribed tumour, felt ol " "The the the p. 566 . Syd. Soc., 1848; or, Cuelius Aurelianus de Morbis Acut. et Chron., lib. iii, cap. iv.-De Jecorosis. Amstelodami, CIDIJCCIX.)

cap. iv.-De Jecorosis. Amstelodami, CI drium, extending upwards as far as the clavicle."-(The Seven Books of P. A Ein., by F. Adams, LL.D., book iii, sect. xlvi, p. 560. Syd. Soc., 1848.-On Affections of F. Adams, LL.D., book iii, sect. xlvi,
the Liver.) See also pp. 567 and 568 .

the "Liver.) See also pp. $5^{6} 7$ and 568 . (cum quâdam illiusce partis gravedine) aliquando ad jugulum, et ad scapulam pro- 